\title{
Microbiological epidemiological history of meningococcal disease in Rio de Janeiro, Brazil
}

Authors

David Eduardo Barroso, $\mathrm{MD} \mathrm{PhD}^{1,2,3}$

Carvalho $\mathrm{DM}^{2}$

Casagrande $\mathrm{ST}^{4}$

Rebelo $\mathrm{MC}^{\mathrm{1}}$

Soares $\mathrm{V}^{1}$

Zahner $\mathrm{V}^{3}$

Solari $\mathrm{CA}^{5}$

Nogueira $\mathrm{SA}^{1,2}$

${ }^{1}$ Instituto Estadual de Infectologia São Sebastião, Rio de Janeiro, RJ, Brazil. ${ }^{2}$ Department of Preventive Medicine, Universidade Federal do Rio de Janeiro, Rio de Janeiro, RJ, Brazil. ${ }^{3}$ Department of Biochemistry and

Molecular Biology, Instituto Oswaldo Cruz, Rio de Janeiro, RJ, Brazil. ${ }^{4}$ Bacteriology Section, Instituto Adolfo Lutz, São Paulo, SP, Brazil. ${ }^{5}$ Department of Bacteriology, Instituto Oswaldo Cruz, Rio de Janeiro, RJ, Brazil.

Submitted on: 06/1/2009 Approved on: 11/19/200

Correspondence to: Dr. David E. Barroso, Laboratório de Sistemática Bioquímica, Instituto Oswaldo Cruz Av. Brasil, 4365

Rio de Janeiro - RJ Brazil

CEP: 21040-900

E-mail: barroso@ioc.

fiocruz.br

Phone: +55-21-38658228

Fax: +55-21-25903495

D.E. Barroso was supported by the Conselho Nacional de Desenvolvimento Científico e Tecnológico - CNPq (grant 141508), but the study sponsor had no involvement to declare.

\begin{abstract}
The main objectives of the present study were to investigate the clinical and laboratory features of meningococcal disease in the city of Rio de Janeiro, Brazil, during the overlap of 2 epidemics in the 1990s. We conducted a study of a series of cases of meningococcal disease admitted in a Meningitis Reference Hospital. All clinical isolates available were analyzed by means of microbiological epidemiological markers. In 1990, Neisseria meningitidis serogroup B:4,7:P1.19,15, 1.7,1 sulfadiazine-resistant of the ET-5 complex emerged causing epidemic disease. Despite mass vaccination campaign (VaMengoc B $+\mathrm{C}^{\circledR}$ ), the ET-5 clone remained hyperendemic after the epidemic peaked. In 1993 to 1995, an epidemic of serogroup C belonged to the cluster A4 overlapped, with a significant shift in the age distribution toward older age groups and an increase of sepsis. Serogroup C epidemics are a recurrent problem in Rio de Janeiro, which can be hindered with the introduction of a conjugate vaccine. We hope the data presented here brings useful information to discuss vaccines strategies and early management of suspected cases.
\end{abstract}

Keywords: Neisseria meningitidis, meningococcal disease, epidemic, meningitis, sepsis.

[Braz J Infect Dis 2010;14(3):242-251] @Elsevier Editora Ltda.

\section{INTRODUCTION}

The Rio de Janeiro state, Southeast of Brazil, had a total population in 2000 of 14,391,282 inhabitants, with 5,857,904 people living in the city of Rio de Janeiro, the Capital of the state. The first confirmed epidemic due to serogroup C disease was registered in the beginning of the 1970s, when a mass vaccination campaign against $N$. meningitidis serogroup $\mathrm{A}$ and $\mathrm{C}$ was implemented in $1975 .{ }^{1}$ The epidemic strain was characterized as phenotype 2a:P1.5, 1.2 genetically related to the ET-37 complex. ${ }^{2}$ In the 1980 s, 1408 cases of meningococcal disease were reported, with incidence of $1-5$ cases $/ 100,000 / \wedge$ year (Rio de Janeiro City Health Department). Since 1985, a steady increase of serogroup B clinical isolates was observed, initially attributed to an improvement in the laboratory diagnostic procedures in identifying meningeal pathogens (Figure 1). Another increase of serogroup C disease was observed in 1988 and it peaked in the next year (Figure 1), mainly due to sero-subtype 2a:P1.2, which motivated the use of polysaccharide specific vaccine in some parts of the Rio de Janeiro state.
From 1990 to 1999, the Rio de Janeiro City Department of Health received the notification of 4147 cases of meningococcal disease (rates $5-10 / 1100,000 /$ year), which represent about $50 \%$ of all reported cases in the state of Rio de Janeiro. In 1990, the incidence rate reached $7.3 / 100,000$ in the city of Rio de Janeiro, with isolates of $N$. meningitidis serogroup B (91\%) predominating in cases diagnosed (Figures $1,2)$. These group B organisms express a class 3 outer membrane protein, many times characterized as serotype $4(82 \%)$ and with a class 1 protein characterized as $\mathrm{P} 1.15$ (45\%); 55\% were B:4:nt. A mass vaccination campaign using the VaMengoc $\mathrm{B}+\mathrm{C}^{\circledR}$ (Finlay Institute) was conducted in Rio de Janeiro in the target population aged 6-months to 9 -years. ${ }^{3}$ This vaccine is composed of $65-95 \mathrm{kD}$ high molecular weight subcapsular proteins and serotype-specific protein phospholipids from a Cuban B:4:P1.15 strain added to serogroup $\mathrm{C}$ polysaccharide, and combined with aluminum hydroxide. The impact of this intervention in the incidence rates was not significant and the disease level did not return to that found before the rise of serogroup B:4 organisms (Figure 2). In 1993, 
Figure 1: Annual distribution of Neisseria meningitidis capsular serogroups causing invasive disease in the city of Rio de Janeiro, 1975-2008.

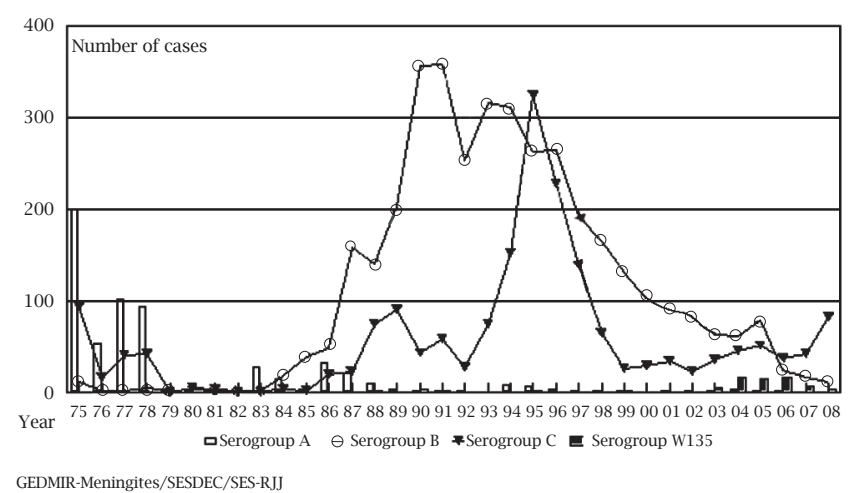

Figure 2: Annual incidence rates of meningococcal disease and indications of mass immunizations campaigns in the city of Rio de Janeiro, 1974-2008.

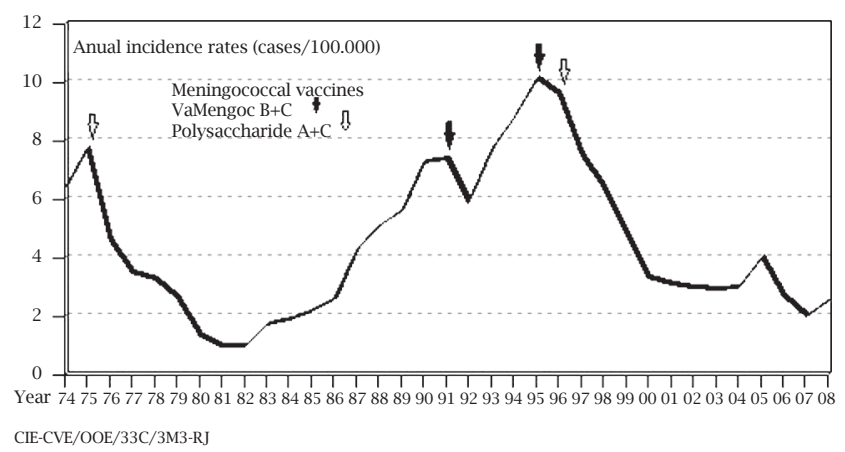

N. meningitidis serogroup $\mathrm{C}$ gave rise to a new increase in meningococcal disease cases and in the next year an epidemic took place. A campaign with the vaccine VaMengoc $\mathrm{B}+\mathrm{C}^{\circledR}$ was extended to all children up to 13 -years old (Figures 1,2). The intervention did not take into account a shift in the age-distribution of the disease and it did not halt an epidemic of meningococcal disease due to serogroup C. In 1995, the epidemic peaked, with a recorded incidence of $>10 / \backslash 100,000$ (Figure 2), which motivated a second vaccination campaign to individuals aged 14 to 30 years with a serogroup $\mathrm{C}$ polysaccharide vaccine. During that year, N. meningitidis serogroup C represented 57\% of all patients' isolates, with a class 2 protein normally characterized as serotype $2 \mathrm{~b}(65 \%)$ or $2 \mathrm{a}(21 \%)$; of the C: $2 \mathrm{~b}$ strains, $93 \%$ were C:2b:nt.

The Infectious Diseases State Institute São Sebastião is a meningitis reference hospital, located in the city of Rio de Janeiro, strategically built close to the harbor basin in 1889 to receive patients with yellow fever, then epidemic in the city. In the 1990s, its Epidemiological Surveillance Unit detected two epidemic waves of disease caused first by serogroup B followed a few years later by serogroup C N. meningitidis. We have studied the clinical and laboratory features of meningococcal disease based on the records of the State
Reference Hospital, between 1990 and 1996, to describe the clinical manifestations and the characterization of N. meningitidis clinical isolates using different microbiological epidemiological markers.

\section{MATERIAL AND METHODS}

\section{Setting, study population, and study design}

A retrospective descriptive study was conducted in a series of cases of meningococcal disease admitted between 1990 and 1996 in the Meningitis Reference Hospital, with residence in the city of Rio de Janeiro. During the study period, the Reference Hospital had admitted 77\% (2413/3150) of all reported cases in that city. Also, its laboratory of bacteriology has identified the species and characterized the capsular serogroup of more than $90 \%$ (1284/1426) of all known $N$. meningitidis clinical isolates in the Rio de Janeiro region (Rio de Janeiro City Department of Health). We divided the study in three defined periods: 1990 to 1992 (epidemic serogroup B disease), 1993 to 1995 (epidemic serogroup C disease), and 1996 (post-vaccination campaign).

\section{Case definition and data collection}

Meningococcal disease patients were defined as confirmed cases - culture (heated blood agar) or antigen detection (latex agglutination kit, bioMérieux ${ }^{\circledR}$ ) or direct smear (Gram stain) - or probable cases - a clinical picture with fever of abrupt onset and suggestive hemorrhagic skin lesions - whenever conventional bacteriological methods were negative or unavailable. Latex agglutination test were only available from 1993 onwards. A census of patients with meningococcal disease was carried out based on diagnosis at admission and discharge. Medical charts and laboratory records of cases enrolled were carefully reviewed.

\section{Collection, characterization and typing of clinical isolates of $N$. meningitidis}

All viable $N$. meningitidis isolated from CSF or blood from meningococcal disease patients (meningitis and/or sepsis) between 1990 and 1996 were analyzed in a single block of time by means of microbiological epidemiological markers. The growth of one oxidase-positive colony, with the appearance of Gram-negative diplococci was identified by a negative $\beta$-galactosidase test and the ability to oxidize glucose and maltose but not lactose and sucrose in cystine tryptic agar. The serogroup of $N$. meningitidis was determined by means of slide agglutination with specific antiserum groups A, B, C, $W_{135}, Y, 29 E, X$, and Z. Non-groupable strains were genetically related to groupable isolates found in the population using genogrouping polymerase chain reaction (PCR) assays as previously reported. ${ }^{4}$ Sero-subtyping has been performed using whole-cell bacterial suspension and monoclonal antibodies in the National Meningitis Refer- 
ence Centre, Adolfo Lutz Institute, São Paulo. Minimum inhibitory concentration (MIC) of penicillin (relative resistant $0.12-0.25 \mu \mathrm{g} / \mathrm{mL}$; resistant $\geq 0.5 \mu \mathrm{g} / \mathrm{mL}$ ), rifampicin (relative resistant $1 \mu \mathrm{g} / \mathrm{mL}$; resistant $\geq 2 \mu \mathrm{g} / \mathrm{mL}$ ), and sulfadiazine (resistant $\geq 8 \mu \mathrm{g} / \mathrm{mL}$ ) were determined by means of E-test strips (AB BIODISK ${ }^{\circledR}$ ) on Müller-Hinton agar (OXOID ${ }^{\circledR}$ CM0337) supplemented with 5\% sheep blood following the manufacture's instruction. Culture plates were incubated at $35^{\circ} \mathrm{C}$ in a candle jar for 24 hours before reading.

Multilocus enzyme electrophoresis (MLEE) was performed and analyzed as described by Selander et al. (1986). ${ }^{5}$ The overall genetic relatedness of N. meningitidis was examined by an analysis of electrophoretically demonstrable allelic variation at 13 structural genes encoding enzymes in 56 serogroup B, 175 serogroup C, and 2 serogroup $\mathrm{W}_{135}$ isolates, recovered from meningococcal disease patients between 1990 and 1995. The electrophoretic types (ETs) were determined by analysis of allelic variations in 13 enzymes assayed, and each unique set of alleles was defined as a multilocus enzyme genotype (ET). Allele profile of each clinical isolate was compared with those previously described; however ET numbers were not cognate with those previously assigned.

\section{Data analysis}

We have summarized the clinical presentation of cases enrolled in three categories taking into account clinical evidence of sepsis - hemorrhagic skin lesions - and laboratory results for biological specimens - cerebrospinal fluid (CSF) white blood cell (WBC) count: meningitis (absence of hemorrhagic skin lesions and CSF WBC count $>10$ per $\mathrm{mm}^{3}$ ), sepsis and meningitis (hemorrhagic skin lesions and CSF WBC count $>10$ per $\mathrm{mm}^{3}$ ) or sepsis (hemorrhagic skin lesions and CSF WBC count $\leq 10$ per $\mathrm{mm}^{3}$ or fever and hemorrhagic skin lesions in the absence of diagnostic lumbar puncture). Co-primary and secondary cases were used to identify when household members became ill with meningococcal disease following onset of the initial case before or after 24 hours in their household, respectively. Patients were stratified into the following age categories: < 1 y, 1-4 y, 5-9 y, 10-14 y, 15-19 y, 20-49 $y, \geq 50 \mathrm{y}$. Clinical picture has been defined as prodromus - sore throat, otalgia, and fits (sneezing, cough or nasal drainage ) - and signs and symptoms recorded at presentation - fever, neck stiffness, headache, vomits, petechial rash, extensive ecchymoses, conjunctivitis, abdominal pain, diarrhea, arthritis, convulsion, systemic shock, localized neurologic signs. Time between onset of disease and hospital admission, time of hospitalization, and outcome (discharge, death or transference) were categorized in hours. Information of pre-admission antibiotic treatment was collected. Also, we have used the outcome data that were available at hospital discharge.

\section{Statistical analysis}

Clinical and epidemiological data were analyzed using Epi Info $^{\mathrm{TM}}$ (Version 3.3.2, CDC). The heterogeneity of proportions between groups was compared using the chi-squared test with Yates's correction or by Fisher's exact test for statistical significance. All results for continuous variables are expressed by means. Exact binomial 95\% confidence intervals (CI) are reported.

Data generated by MLEE were analyzed as proposed in the report of Selander et al. 1986. Briefly, an index of genetic relatedness was determined by weighing the degree of diversity at each of the 13 enzyme loci (electromorphic profile), and similarities among the ETs were assessed by phylogenetic analysis. Genetic diversity $(h)$ at an enzyme locus among either ETs or isolates was calculated from allele frequencies $(h)$. Mean genetic diversity is the arithmetic average of $h$ values over all loci. Genetic distance $(d)$ between pairs of ETs was expressed as the proportion of enzyme loci at which dissimilar alleles occurred (mismatches). A distinctive cluster of ETs, designated as ET-complex, is composed by a group with identical allele profile or ETs with the occurrence of dissimilar alleles at $1-2$ ( $\mathrm{d}$ of 0.08 to 0.15 ) of the 13 loci. Numerical analysis of MLEE data based on 13 enzyme loci was performed using the NTSYS-pc version software package (Rolf FJ, Exeter Software ${ }^{\circledR}$ ) and affinities among strains were calculated using the Dice coefficient. The similarity matrix was transformed into a dendogram by means of unweighed pair group method with arithmetic averages (UPGMA) algorithm.?

\section{RESULTS}

From 1990 to 1996, we have found through the hospital and laboratory records 2413 diagnosed cases of meningococcal disease. After review, we excluded 75 cases because their diagnoses did not meet the criteria for inclusion. Of the remaining $2338(90-92=908 ; 93-95=1059 ; 96=371)$ patients, medical charts and laboratory records were thoroughly reviewed. Of these, $3 \%$ had not been notified to the Rio de Janeiro City Department of Health. Diagnostic lumbar puncture was performed at presentation in $94 \%$ (2197/2338) of the patients enrolled. In addition to 1644 (70\%) patients confirmed through conventional bacteriology, we included 694 (30\%) probable cases with hemorrhagic rash and either meningitis and/or sepsis. Of these confirmed cases, $78 \%$ (1284) were detected solely by culture, 12\% (194; $93-95=117 ; 96=77)$ by antigen detection, and 10\% (166) by direct smear. The proportion of culture-proven cases were $63 \%$ (567), 53\% (562), and 41\% (155) according with the three periods of the study. In all, $11 \%(90-92=11 \%$; 93 $95=14 \% ; 96=16 \%$ ) of the patients had received at least on dose of antibiotics by injection before hospital admission, with the presence of a petechial rash in $80 \%$ of them. A few 
patients $(1 \%$; 25/2338) had history of recurrent meningococcal disease, with 2 or 3 previous episodes. Of the total, $3 \%$ of the patients (75/2338) referred to a case of meningococcal disease previously diagnosed in their household, which could be defined as co-primary $(\mathrm{n}=38)$ or secondary cases $(\mathrm{n}=37)$. The number of secondary cases was higher between 1993 and 1995 (4\%; 95\% CI 3-6\%), compared with the previous period $(2 \%$; $95 \%$ CI $1-4 \%)\left(\chi^{2}=5 ; p<0.05\right)$.

Although meningococcal disease affected more males $(55 \%)$ than females (45\%) above 49 -years of age, there was a preponderance of females $(62 \%)$ with infection $\left(\chi^{2}=6\right.$; $\mathrm{p}<0.05)$. The relation male:female was 0.62 in patients older than 49 years. The overall average age was 10 -years old (range, 23 days to 72 years) and the median was 6-years old. The average age of serogroup B meningococcal disease patients was 11 -years old (median $=6$-years) and for patients from whom $N$. meningitidis serogroup $C$ was recovered the average was 12 -years old (median $=9$-years). For those confirmed cases, $35 \%(90-92=33 \%$; $93-95=37 \%)$ and $49 \%$ $(90-92=47 \% ; 93-95=49 \%)$ were in the age category 10 to 29 -years $\left(\chi^{2}=19 ; \mathrm{p}<0.01\right)$, respectively. There was a change in the age distribution toward older age groups in the serogroup $\mathrm{C}$ epidemic years, with a significant increase in the number of cases in teenagers 15 to 19 -years old $(90-92=6 \%$; $\left.93-95=12 \% ; \chi^{2}=18.7, \mathrm{p}<0.01\right)$. The seasonal pattern of infection for these serogroups had discrete distinction, the highest number of infections being in the winter season for serogroup B and in the spring for serogroup C.

The prodromus registered at presentation were fits (8\%), sore throat $(4 \%)$, and otalgia $(2 \%)$. Fits were more prevalent in infants (13\%) and adults 20 to 49 -years (12\%). Sore throat was a more frequent complaint in teenagers 15 to 19 -years $(9 \%)$. The clinical signs and symptoms of confirmed and sus- pected cases of meningococcal disease and specific features of the disease according to the age of patients at presentation are presented in Table 1. Some clinical features associated with a worse prognosis, i.e., extensive ecchymoses, diarrhea, absence of neck stiffness, and shock were more frequent among suspected cases $(\mathrm{p}<0.05)$. There were not major differences in the clinical pattern of serogroup $B$ and C disease. A suggestive rash was associated with $55 \%$ of serogroup B disease, whilst it was associated with $57 \%$ of serogroup C disease $(p>0.05)$. However, the presence of a petechial rash had a significant variation between the first (65\%; 95\%CI 61\%-68\%) and second (73\%; 95\%CI 70\%$76 \%)$ period of this study $\left(\chi^{2}=14 ; \mathrm{p}<0.01\right)$. This trend was also noticed among confirmed (90-92 $=50 \%$; $93-95=$ $\left.60 \% ; \chi^{2}=12 ; \mathrm{p}<0.01\right)$ and suspected cases $(90-92=89 \%$; $\left.93-95=94 \% ; \chi^{2}=3.7 ; \mathrm{p}=0.05\right)$. Purpura was markedly increased in children (5-9 years: $72 \% \times 84 \%$ ), teenagers (15 to 19 -years: $56 \% \times 72 \%)$, and adults $(20-49$ years: $56 \% x$ 70\%) after $1992(\mathrm{p}<0.05)$.

Patients were classified as meningitis (30\%), sepsis and meningitis (58\%), and sepsis (12\%). The percentage of patients confirmed through microbiological techniques according to the clinical manifestation was $90 \%, 56 \%$, and $16 \%$, respectively. The proportion of patients presenting with sepsis was $8 \%(95 \%$ CI $6 \%-10 \%)$ between 1990 and 1992, which turned to be $15 \%$ (95\%CI 13\%-17\%) during the serogroup $\mathrm{C}$ epidemic years $\left(\chi^{2}=21 ; \mathrm{p}<0.01\right)$. Although the rise of patients classified as sepsis was observed in all age categories, it only reached statistical significance in children 5 to 9 -years and adults 20 to 49 -years $(\mathrm{p}<0.01)$. The number of patients with sepsis had a statistically significant increase both in culture-proven $(90-92: 2 \% ; 93-95:=7 \% ; 96:=10 \%)$ and suspected cases (90-92: 18\%; 93-95: 31\%; 96: 39\%).

Table 1. Proportions (\%) of signs and symptoms at presentation of all cases enrolled according to the laboratory results for biological specimens and age category of patients

\begin{tabular}{|lccccccc}
\hline $\begin{array}{l}\text { Signs and symptoms } \\
\text { (\%) }\end{array}$ & $\begin{array}{c}\text { Confirmed } \\
\text { cases }\end{array}$ & $\begin{array}{c}\text { Suspected } \\
\text { cases }\end{array}$ & $\begin{array}{c}\text { Infants } \\
(<\mathbf{1} \text { year) }\end{array}$ & $\begin{array}{c}\text { Children } \\
(\mathbf{1 - 9} \text { year) }\end{array}$ & $\begin{array}{c}\text { Teenagers } \\
(\mathbf{1 0 - 1 9} \text { year) }\end{array}$ & $\begin{array}{c}\text { Adults } \\
\text { (20-49 year) }\end{array}$ & $\begin{array}{c}\text { Elderly } \\
(>49 \text { year) }\end{array}$ \\
\hline Fever & 95 & 95 & 97 & 96 & 92 & 92 & 96 \\
\hline Headache & 56 & 48 & $\mathrm{n} / \mathrm{a}$ & 48 & 86 & 82 & 86 \\
\hline Petechiae & 54 & 89 & 45 & 75 & 68 & 56 & 54 \\
\hline Extensive ecchymoses & 21 & 41 & 18 & 34 & 27 & 22 & 18 \\
\hline Neck stiffness & 86 & 67 & 59 & 77 & 87 & 89 & 90 \\
\hline Convulsion & 6 & 8 & 7 & 8 & 5 & 5 & 14 \\
\hline Arthritis & 10 & 13 & 9 & 12 & 8 & 14 & 21 \\
\hline Diarrhoea & 3 & 6 & 9 & 4 & 3 & 4 & 18 \\
\hline Impaired consciousness & 47 & 42 & 31 & 45 & 46 & 57 & 68 \\
\hline Vomitus & 79 & 70 & 67 & 76 & 82 & 71 & 71 \\
\hline Abdominal pain & 3 & 4 & $\mathrm{n} / \mathrm{a}$ & 4 & 4 & 0 & 4 \\
\hline Localized neurologic signs & 3 & 2 & 5 & 2 & 3 & 7 & 4 \\
\hline Systemic shock & 7 & 24 & 14 & 15 & 12 & 11 & 11 \\
\hline
\end{tabular}


Outcome and time of hospitalization according to age category, sex, and clinical manifestation are summarized in Table 2. Almost all patients either received ampicillin $(59 \%)$ or penicillin (40\%) for a mean time of 7 to 10 days. The patients have reached the hospital within a mean time of 48 hours (range, 1 hour to 15 days) of the start of their illness. This interval was $\leq 24$ hours for $59 \%$ of the patients at presentation $(\leq 12 \mathrm{~h}=13 \% ; 13-24 \mathrm{~h}=46 \%), 25$ 48 hours for $18 \%, 3-7$ days for $21 \%$, and $>7$ days for $2 \%$. Of the patients who survived, $85 \%$ had $\geq 24$ hours history of their illness. Ninety two percent of the deaths occurred in the first 2 days after the start of the treatment; $70 \%$ occurred during the first 12 hours (23\% at presentation; $25 \%$ first two hours; 52\% 3-12 hours). The case-fatality rates for sepsis decreased during the study period $(90-92=45 \%$; $93-95=28 \%$; $96=30 \%$ ).

About $90 \%$ of the patients with a fatal outcome had vasculitic skin lesions; 39\% were confirmed cases and $61 \%$ were probable cases $\left(\chi^{2}=7 ; p<0.01\right)$. Patients with purpura $(20 \%)$ or extensive ecchymoses $(63 \%)$ had a higher chance to evolve with systemic shock compared with those without a suggestive rash $(2 \%)(\mathrm{p}<0.01)$. Serogroup C disease had a slight higher chance to be associated with a fatal outcome $(8 \%)$ than serogroup B disease $(6 \%)(p>0.05)$. Nevertheless, this is difficult to be correctly estimated because only $43 \%$ of the deaths were confirmed cases; besides, confirmed cases had a lower chance to die $(7 \%$; $90-92=5 \%$; $93-95=$
$7 \% ; 96=6 \%)$ compared with probable cases $(17 \%, 90-92=$ $17 \%$; $93-95=13 \%$; $96=14 \%)(\chi 2=40 ; p<0.01)$.

In 1990 to 1992, serogroup B predominated in cases diagnosed (89\%). Serotype 4 was associated with $79 \%$ of serogroup B clinical isolates; $47 \%$ were B:4:P1.15 and 52\% were B:4:nt.

In 1993, the introduction of the P1.7 monoclonal antibody in the sero-subtyping panel disclosed that $35 \%$ of the B:4 (80\%) strains expressed this subtype; $49 \%$ were $\mathrm{B}: 4: P 1.15$. It is necessary to point out the concomitant decline of the B:4:nt isolates to $16 \%$ (93 = 31\%; $94=4 \%$; 95 $=14 \% ; 96=4 \%)$. Subsequently they were characterized as B:4,7:P1.19,15 and B:4,7:P1.7,1. Serogroup C represented $9 \%$ of all clinical isolates within the first period. Serotype 2a was usually associated with subtype P1.2 and serotype 2b with subtype P1.3; 46\% were C:NT:nt. In 1993 to 1996, $43 \%$ of the confirmed cases were due to capsular serogroup C. At that time, $54 \%$ of $N$. meningitidis serogroup C patients' isolates expressed a class 2 protein characterized as $2 \mathrm{~b}$ and $26 \%$ as $2 \mathrm{a} ; 16 \%$ were C:NT:nt. Of the C:2b isolates, $82 \%(93=29 \%$; $94=62 \%$; $95=93 \%$; $96=96 \%)$ were nonsubtypable (nt). It was shown that most of C:2b isolates express the subtype P1.10, which was found in $94 \%$ $(94=95 \% ; 95=93 \% ; 96=92 \%)$ of tested strains. Four serogroup C organisms express a class 3 outer membrane protein, characterized as sero-subtype 4:P1.15, P1.7, nt. Only one N. meningitidis recovered was designated as non-

Table 2. Outcome and time of hospitalization according to age, sex, and clinical manifestation of all cases enrolled

\begin{tabular}{|lcccccc}
\hline & \multicolumn{2}{c}{ Patients (\%) per days of hospitalization } & \multicolumn{3}{c}{ Case-fatality rates (\%) } \\
\hline $\begin{array}{l}\text { Age group } \\
\text { (years) }\end{array}$ & $\mathbf{1 0}$ & $\mathbf{1 1} \mathbf{~ a ~ 1 5}$ & $\mathbf{1 0}$ & Overall & Male & Female \\
\hline$<1$ & 27 & 32 & 41 & 15 & 18 & 13 \\
\hline $1-4$ & 67 & 25 & 8 & 10 & 10 & 9 \\
\hline $5-9$ & 76 & 19 & 5 & 12 & 10 & 13 \\
\hline $10-14$ & 87 & 10 & 3 & 5 & 4 & 5 \\
\hline $15-19$ & 82 & 16 & 2 & 5 & 3 & 8 \\
\hline $20-49$ & 73 & 17 & 10 & 6 & 5 & 7 \\
\hline$\geq 50$ & 57 & 25 & 18 & 22 & 19 & 22 \\
\hline Total & 71 & 20 & 9 & 10 & 9 & 10 \\
\hline Meningitis & 63 & 24 & 13 & 2 & 3 & 3 \\
\hline Septicaemia + Meningitis & 73 & 19 & 8 & 9 & 8 & 9 \\
\hline Septicaemia & 88 & 9 & 3 & 33 & 32 & 35 \\
\hline
\end{tabular}


groupable (NG:2a:P1.2), which was later genetically related to the serogroup $\mathrm{W}_{135}$ by means of PCR.

On a nonselective basis, $13 \%$ of the $N$. meningitidis serogroup B stratified by sero-subtype were randomly selected and analysed by MLEE. In the collection of serogroup B isolates, 4 of the 13 enzyme loci were monomorphic and 9 were polymorphic for two to four alleles. The average number of alleles per locus was 1.9. A total of 9 distinctive multilocus enzyme genotypes were identified, for which mean genetic diversity per locus was 0.33 . There was less genetic diversity per locus among isolates $(h=0.15)$, a result of the connected fact that one ET was represented by multiple isolates. The majority $(68 \%)$ of serogroup B (B:4:P1.15 = 53\%; B:4:P1.7 $=24 \% ; \mathrm{B}: 4: \mathrm{nt}=18 \%$; B:2a:P1.2 = 5\%) organisms presented a unique set of alleles defined as ET-2 (B:4,7:P1.19,15; $\mathrm{N} 44 / 89$ ) of the distinctive cluster of ETs, designated as the ET-5 complex (Figure 3). Also, 16\% were represented by four clones genetically related to this complex diverging from the ET-2 at a genetic distance of $0.08-0.15$. The other serogroup $\mathrm{B}$ isolates (16\%) were assigned to four ETs not related to the ET-5 complex $(d=0.31-0.46)$. The ET-1 (B:15:P1.7,16; $\mathrm{H} 44 / 76)$ of the ET-5 complex was represented by four N. meningitidis C:4 isolates. All the organisms within the ET-5 complex showed resistance to sulphonamide (MIC $\geq 8 \mu \mathrm{g} / \mathrm{mL}$ ) at an average MIC of $146 \mu \mathrm{g} / \mathrm{mL}$ (range,
8 - $256 \mu \mathrm{g} / \mathrm{mL})$; one isolate was relatively resistant to penicillin (MIC of $0.125 \mu \mathrm{g} / \mathrm{mL}$ ).

All serogroup C patients' isolates sero-subtyped available (80\%) were selected to determine multilocus enzyme genotypes. In the collection of serogroup $C$ isolates, 9 of the 13 enzyme loci were polymorphic for two to three alleles. The average number of alleles per locus was 1.9. A total of 19 distinctive multilocus enzyme genotypes were identified, for which mean genetic diversity per locus was 0.27 . There was less genetic diversity per locus among isolates $(h=0.07)$, reflecting the circumstance that one unique ET was represented by the majority of the isolates $(n=142)$. The ET-40 (C:2b:P1.3; N1002/90) was represented by $81 \%$ of the serogroup $\mathrm{C}$ organisms (C:2a:P1.2 = 25\%; C:2a:P1.3 = 1\%; C:2a:nt = 11\%; C:2b:P1.10 = 58\%; $\mathrm{C}: 2 \mathrm{~b}: \mathrm{nt}=5 \%$, which belongs to a cluster of ETs, designated as the cluster A4 (Figure 3). There were 14\% assigned to eleven ETs related to this cluster, which diverged from the ET-40 at d of $0.08-0.15$. Only $5 \%$ of the serogroup C isolates were identified to multilocus genotypes unrelated to anything else in the database, which diverged from the ET-40 at d of $0.23-0.38$. One $N$. meningitidis serogroup $\mathrm{W}_{135}: 19$ :nt isolate genetically belonged to the cluster A4, with an allele profile closely related to the ET-40 ( $d$ of 0.08). Of the organisms within the cluster A4, $36 \%$ were sulfadiazine-resistant ( $\mathrm{MIC} \geq 8 \mu \mathrm{g} / \mathrm{mL}$ ) and one was relative resistant to penicillin (MIC of $0.125 \mu \mathrm{g} / \mathrm{mL}$ ).

Figure 3: Genetic relationships of multilocus enzyme genotypes of Neisseria meningitidis strains.

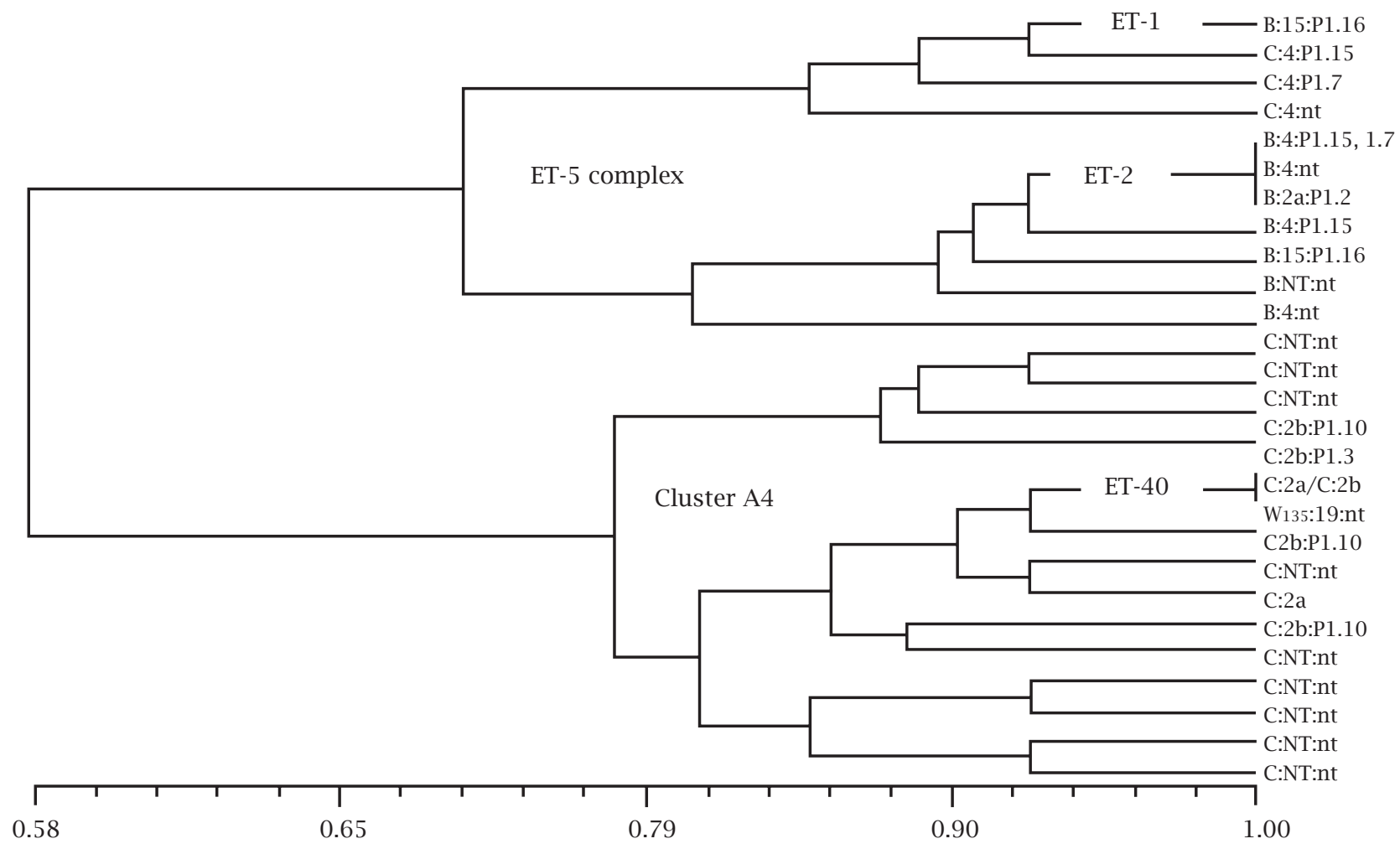

Dice coefficient 


\section{DISCUSSION}

Meningococcal disease is a major infectious fever emergency, which remains a significant cause of death in young children. ${ }^{8}$ The epidemics caused by serogroup B of the ET-5 complex have affected mainly children below 5 -years of age with a peak of incidence in adolescents. ${ }^{3,9-12}$ Alternatively, in Great Britain phenotypes associated with the ET- 5 complex caused a much smaller proportion of infections in children $<4$-years of age than in patients $>5$-years of age. ${ }^{13}$ Although meningococcal disease affects mainly children during epidemics the proportion of patients aged greater than 4-years increase significantly. ${ }^{14-17}$ Serogroup $\mathrm{C}$ disease and the median age of cases have steadily risen in Europe and North America during the last decade..$^{18-25}$

The distribution of cases of meningococcal disease by sex showed a predominance of males, but when they were stratified by age group there was a predominance of female older than 49-years. Nevertheless, in Europe there was also a preponderance of females with infection $(\mathrm{M}: \mathrm{F}=0.94)$ at 15 to 17 -years of age. ${ }^{13,26}$ Although a statistically significant influence of sex (female) in the chance to die was demonstrated in a previous investigation, ${ }^{27}$ this could not be supported elsewhere. ${ }^{28-30}$

In the 1990s, an increase of patients presenting with sepsis alone has been associated with the emergence of serogroup C invasive infection, especially in children ${ }^{18,20}$ and adolescents. ${ }^{30}$ In fact, some studies have pointed out serogroup C disease with a worse outcome. ${ }^{21,25,30,31}$ Despite of that, several reports have shown that case-fatality rates have fallen in recent years despite the observation that sepsis alone has arisen..$^{20,22,32,33}$ This is the result of several factors, highlighting immediate administration of antibiotic therapy, ${ }^{33}$ the recognition and treatment of patients who may have complications, ${ }^{34}$ the establishment of specialized mobile intensive care teams, ${ }^{35}$ centralization of care of seriously ill patients in an intensive care unit (ICU), ${ }^{32}$ and dissemination of guidance about early recognition and management. ${ }^{36,37}$

Clinical presentation of meningococcal disease in 2338 patients studied in the city of Rio de Janeiro demonstrated the importance of hemorrhagic rash, a clinical manifestation of sepsis and the first classic symptom of meningococcal disease to spring. The serogroup $\mathrm{C}$ epidemic in Rio de Janeiro was accompanied both by an excess of patients with a suggestive rash and an increase of cases diagnosed as sepsis alone, an indication of the spread of a hipervirulent strain when the "force of infection" was high. Despite the increase in sepsis the overall case-fatality rate remained stable, and for patients with sepsis decreased. A possible bias of investigations of meningococcal disease conducted in a Reference Centre is the exclusion of the most severe cases, which might have not had the chance to reach it. An excess of deaths at presentation (23\%) and following hospital admission (25\%) is an indicative that the most severe cases did reach the Ref- erence Hospital. Unfortunately, many of those patients who died reached the Hospital without prior antibiotic therapy and safe interhospital transfer.

Initial unspecific symptoms and clinical presentation differed according to the age of patients. Infants were more likely to develop meningitis in the absence of neck stiffness and petechiae, preceded by an antecedent of upper respiratory infection. Diarrhea, an unspecific sign possible associated with diagnostic delay and death, ${ }^{38}$ was frequent in the very young and the very old. It is sometimes an early feature of the condition, ${ }^{39}$ and it can be severe enough to suggest a diagnosis of acute gastroenteritis. ${ }^{16}$ Patients above 49 -years of age were distinguished by a clinical picture of meningitis without a rash, neck stiffness, impaired consciousness, and convulsions. Both groups had a presentation and antecedents which might have led to diagnostic delays and problems in the initial case management; thus, it may explain in part the highest case-fatality rates. They also necessitated a longer time of hospitalization (Table 2). Normally, children developed sepsis or meningitis with a sepsis component, accompanied by extensive purpura, systemic shock, and late hospital complications. Teenagers and adults had a higher chance to develop meningitis with the classic triad: fever, headache, and neck stiffness. In spite of that, teenagers were more likely to have a vasculitic rash, whereas adults had impaired consciousness and localized neurologic signs.

In both epidemics periods a clonal structure could be defined by means of MLEE, a characteristic of the population biology of this bacterium during epidemic waves of disease. ${ }^{40,41}$ Serogroup B epidemic disease has initially evolved gradually and after the epidemic peak it remained throughout the decade on a sustained hiperendemic level (Figures 1, 2). The clones of the ET-5 complex underwent several recombination events during the intercontinental spread, ${ }^{42}$ that have generated the B:4,7:P1.19,15 variant responsible to epidemic disease in the south and south-east of Brazil. ${ }^{12,43}$ It is important to notice, the surface antigen (PorA) P1.7,1 variant emerged in the Rio de Janeiro Region, which had not been associated with the B:4 Brazilian strains before. ${ }^{12,43}$ These clones were sulfadiazine-resistant, in contrast to serogroup and serotype, an essentially invariant property of clones of the ET- 5 complex. ${ }^{10,44}$ The recovery of C:4 strains of the ET-5 complex (Figure 3) suggests that capsule switching has occurred after the mass vaccination campaigns, probably as the result of transformation and horizontal DNA exchange in vivo. ${ }^{45}$ The C:4,7:P1.19,15 strain is noteworthy to have recently caused a case cluster in south of Brazil. ${ }^{46}$

The epidemic of serogroup C disease rapidly evolved after 1993, presenting a similar clinical and epidemiological pattern found in simultaneous events elsewhere. ${ }^{42,47-50}$ The two striking features of the serogroup $\mathrm{C}$ epidemics in the 1990s were a changing in clinical presentation, with the rise of sepsis, and a shift towards a higher incidence of the dis- 
ease in adolescents. ${ }^{18-21,25,30} \mathrm{~A}$ higher incidence of disease in adolescents has serious implications for community health, due to their extensive net of social contacts and the possibility of acquisition of infection in work or study or social activity places. ${ }^{47,51}$ Clones belonging to the cluster A4 and to the ET-37 complex have been implicated with epidemics of serogroup C in the America and Europe Continents. ${ }^{24,25,31,49,52}$ In the second half of the 1990s the cluster A4 has displaced the ET-37 complex in Spain and Portugal, ${ }^{24,52}$ and more recently in Italy and Poland. ${ }^{31,53}$ In Rio de Janeiro, the cluster A4 epidemic strains often express sero-subtype 2b:P1.10 (Figure 3), which has caused epidemic and hiperendemic waves of disease in other parts of Brazil but expressing an unusual subtype, P1.3., ${ }^{2,11,12}$

Serogroup C disease has emerged in the Rio de Janeiro metropolitan area once more after the year 2000, and now it represents more than $90 \%$ of the clinical isolates (Figure 1 ). The strains have mainly been associated with the phenotypes C:23:P1.14-6, C:4,7:P1.19,15, P1.7.1 sulfadiazineresistant (SR), and, to lesser extent, C:2a:P1.5,2. At least four outbreaks investigated have motivated immediate action in the cities of Parati (2004: C:23:P1.14-6), Rio de Janeiro (2006: C:4,7:P1.7,1 SR), Petrópolis (2007: genogroup C), and Búzios (2008: C:2a:P1.5) (data not shown). The rise of capsular serogroup $\mathrm{W}_{135}$ isolated from clinical cases was also noticed (Figure 1).

Penicillin relative resistance (PenRR) was detected in two N. meningitidis belonging genetically to the ET-5 complex or to the cluster A4. The PenRR strains belonging to a single clone of the cluster A4 was found in Italy a few years ago. ${ }^{53}$ Also, the dissemination of the hypervirulent cluster A4, among PenRR serogroup $\mathrm{C}$ isolates in Portugal has recently been reported..$^{24} \mathrm{~A}$ reduction of the penicillin intermediate breakpoint to $0.094 \mu \mathrm{g} / \mathrm{mL}$ has been suggested when the Etest method is used ${ }^{54}$ however the application of this level of intermediate resistance would not alter our data. The increase of cases of meningococcal disease caused by PenRR isolates has been followed by publications of only a few reports of treatment failure, some of then inconclusive or just showing a prolonged time to abatement of fever. ${ }^{55-58}$

Accumulating clinical experience has gradually outlined the epidemiology of meningococcal disease, including the epidemic and the endemic disease, the usual clinical signs according to age of patients, and causative strains. ${ }^{59}$ Mass vaccination campaign, if appropriately implemented, has been documented to halt an epidemic of meningococcal disease. ${ }^{48}$ Although successful vaccination strategy has to cover all populations at risk of disease sometimes the stock of vaccine is not sufficient or unavailable. ${ }^{60}$ Thus, it is necessary to reinforce that proper case management is the only effective measures against invasive disease, ${ }^{37,61,62}$ and this can be the only remaining strategy during epidemics. ${ }^{60}$ In our context, the routine implementation of serogroup $\mathrm{C}$ glyco- protein conjugate vaccine is of paramount importance, due to the influence of disease burden and periodic epidemics of serogroup C since the 1970s. We hope the data presented here brings useful information to discuss vaccines strategies, revise the guidance to early management of suspected cases, and evolutionary approaches to analysis of $N$. meningitidis strains.

\section{ACKNOWLEDGEMENTS}

D.E. Barroso was supported by the Brazilian National Research Council-CNPq (grant 141508), but the study sponsor had no involvement to declare. We are sincerely thanked to the medical students of the Federal University of Rio de Janeiro, Scientific Initiation Program - Meningitis Research Project, who helped to review the medical charts. Many thanks to Dr. Ana Paula de Lemos at the National Reference Meningitis Centre, Adolfo Lutz Institute who did the serosubtyping. We want to acknowledge the staff of the Infectious Diseases State Institute São Sebastião, Rio de Janeiro and the staff of the Bacteriology Section, Adolfo Lutz Institute, São Paulo. Dr. Silvana T. Casagrande our friend and contributor passed away in 2006.

\section{REFERENCES}

1. DMEG - Doença Meningocócica no Estado da Guanabara. Bol Epidemiol 1974; 6:171-6.

2. Lemos APS, Yara TY, Gorla MCO et al. Clonal distribution of invasive Neisseria meningitidis serogroup C strains circulating from 1976 to 2005 in greater São Paulo, Brazil. J Clin Microbiol 2007; 45(4):1266-73.

3. Noronha CP, Struchiner CJ, Halloran ME. Assessment of the direct effectiveness of BC meningococcal vaccine in Rio de Janeiro, Brazil: a case-control study. Int J Epidemiol 1995; 24(5):1050-7.

4. Pedro LGF, Boente RF, Madureira DJ et al. Diagnosis of meningococcal meningitis in Brazil by use of PCR. Scand J Infect Dis 2007; 39:28-32.

5. Selander RK, Caugant DA, Ochman H, Musser JM, Gilmour MN, Whittam TS. Methods of multilocus enzyme electrophoresis for bacterial population genetics and systematics. Appl Environ Microbiol 1986; 51:873-84.

6. Meningococcal Disease Surveillance Group. Meningococcal disease: secondary attack rate and chemoprophylaxis in the United States, 1974. JAMA 1976; 235:261-265.

7. Sneath PHA, Sokal RR. Numerical Taxomomy. In: Kennedy D, Park R, eds. The Principle and Practice of Numerical Classification. San Francisco: Freeman, 1973: 131-3.

8. Stephens DS, Greenwood B, Brandtzaeg P. Epidemic meningitis, meningococcaemia, and Neisseria meningitidis. Lancet 2007; 369(9580):2196-210.

9. Cartwright KA, Stuart JM, Noah ND. An outbreak of meningococcal disease in Gloucestershire. Lancet 1986; 2(8506):558-61.

10. McGuinness BT, Clarke IN, Lambden PR et al. Point mutation in meningococcal por A gene associated with increased endemic disease. Lancet 1991; 337(8740):514-17.

11. Sacchi CT, Zanella RC, Caugant DA et al. Emergence of a new clone of serogroup C Neisseria meningitidis in São Paulo, Brazil. J Clin Microbiol 1992; 30(5):1282-86. 
12. Bertoncini RCC, Herberts RA, Dário MG, Merlin RC, Miletti LC. Epidemiological study of Neisseria meningitidis strains isolated from cases of meningococcal disease in Santa Catarina State, Brazil. Public Health 2007; 121:880-3.

13. Jones DM, Mallard RH. Age incidence of meningococcal infection England and Wales, 1984-1991. J Infect 1993; 27:83-8.

14. Bell WE, McCormick WF. Meningococcal meningitis. In: Bell WE, McCormick WF, eds. Neurological Infectious in Children. Philadelphia: WB Saunders, 1981:155-75.

15. Peltola H, Kataja JM, Makela PH. Shift in the age-distribution of meningococcal disease as predictor of an epidemic? Lancet 1982; 2:595-7.

16. Greenwood BM. Meningococcal disease. In: Strickland GT, ed. Hunter's Tropical Medicine. Philadelphia: WB Saunders, 1991:385-99.

17. Moore PS, Broome CV. Cerebrospinal meningitis epidemics. Sci Am 1994; 271:38-45.

18. Riordan FA, Marzouk O, Thomson AP, Sills JA, Hart CA. The changing presentations of meningococcal disease. Eur J Pediatr 1995; 154(6):472-4.

19. Ashton FE, Ryan JA, Borczyk A, Caugant DA, Mancino L, Huang D. Emergence of a virulent clone of Neisseria meningitidis serotype $2 \mathrm{a}$ that is associated with meningococcal group C disease in Canada. J Clin Microbiol 1991; 29(11):2489-93.

20. Ramsay M, Kaczmarski E, Rush M, Mallard R, Farrington P, White J. Changing patterns of case ascertainment and trends in meningococcal disease in England and Wales. Commun Dis Rep CDR Rev 1997; 7(4):R49-54.

21. Barquet N, Domingo P, Caylà JA et al. Meningococcal disease in a large urban population (Barcelona, 1987-1992): predictors of dismal prognosis. Barcelona Meningococcal Disease Surveillance Group. Arch Intern Med 1999; 159(19):2329-40.

22. Carrol ED, Thomson AP, Shears P, Gray SJ, Kaczmarski EB, Hart CA. Performance characteristics of the polymerase chain reaction assay to confirm clinical meningococcal disease. Arch Dis Child 2000; 83(3):271-73.

23. Finn R, Groves C, Coe M, Pass M, Harrison LH. Cluster of serogroup $\mathrm{C}$ meningococcal disease associated with attendance at a party. South Med J 2001; 94(2):1192-4.

24. Ferreira E, Dias R, Caniça M. Antimicrobial susceptibility, serotype and genotype distribution of meningococci in Portugal, 2001-2002. Epidemiol Infect 2006; 134(6):1203-7.

25. Smith I, Caugant DA, Hoiby EA, Wentzel-Larsen T, Halstensen A. High case-fatality rates of meningococcal disease in Western Norway caused by serogroup C strains belonging to both sequence type (ST)-32 and ST-11 complexes, 19852002. Epidemiol Infect 2006; 134:1195-202.

26. Scholten RJ, Bijlmer HA, Valkenburg HA, Dankert J. Patient and strain characteristics in relation to the outcome of meningococcal disease: a multivariate analysis. Epidemiol Infect 1994; 112:115-24.

27. Scholten RJ, Bijlmer HA. Excess female fatalities among patients with meningococcal disease. Int J Epidemiol 1995; 24:244-5.

28. Stephens DS, Hajjeh RA, Baughman WS, Harvey RC, Wenger JD, Farley MM. Sporadic meningococcal disease in adults: results of a 5-year population-based study. Ann Intern Med 1995; 123:937-40.

29. Andersen J, Backer V, Voldsgaard P, Skinhoj P, Wandall JH. Acute meningococcal meningitis: analysis of features of the disease according to the age of 255 patients. Copenhagen Meningitis Study Group. J Infect 1997; 34:227-35.
30. Harrison LH, Pass MA, Mendelsohn AB et al. Invasive meningococcal disease in adolescents and young adults. JAMA 2001; 286:694-9.

31. Skoczynska A, Kadlubowski M, Knap J, Szulc M, Janusz-Jurczyk M, Hryniewicz W. Invasive meningococcal disease associated with a very high case fatality rate in the North-West of Poland. FEMS Immunol Med Microbiol 2006; 46:230-5.

32. Pollard AJ, Britto J, Nadel S, DeMunter C, Habibi P, Levin M. Emergency management of meningococcal disease. Arch Dis Child 1999; 80:290-6.

33. Hart CA, Thomson AP. Meningococcal disease and its management in children. Bmj 2006; 333:685-690.

34. Riordan FA, Thomson AP. Recognition, treatment and complications of meningococcal disease. Paediatr Drugs 1999; 1:263-82.

35. Britto J, Nadel S, Maconochie I, Levin M, Habibi P. Morbidity and severity of illness during interhospital transfer: impact of a specialised paediatric retrieval team. Bmj 1995; 311:836-9.

36. Riordan FA, Thomson AP, Sills JA, Hart CA. Who spots the spots? Diagnosis and treatment of early meningococcal disease in children. Bmj 1996; 313:1255-6.

37. Nadel S, Kroll JS. Diagnosis and management of meningococcal disease: the need for centralized care. FEMS Microbiol Rev 2007; 31:71-83

38. Werneck GL, de Carvalho DM, Barroso DE, Cook EF, Walker AM. Classification trees and logistic regression applied to prognostic studies: a comparison using meningococcal disease as an example. J Trop Pediatr 1999; 45:248-51.

39. Thompson MJ, Ninis N, Perera $\mathrm{R}$ et al. Clinical recognition of meningococcal disease in children and adolescents. Lancet 2006; 367:397-403.

40. Achtman M. Molecular epidemiology of epidemic bacterial meningitis. Rev Med Microbiol, 1990; 1:29-38.

41. Bygraves JA, Urwin R, Fox AJ, Gray SJ, Russell JE, Feavers IM, Maiden MCJ. Population genetic and evolutionary approaches to analysis of Neisseria meningitidis isolates belonging to the ET-5 complex. J Bacteriol 1999; 181:5551-6.

42. Guibourdenche M, Hoiby EA, Riou JY, Varaine F, Joguet C, Caugant DA. Epidemics of serogroup A Neisseria meningitidis of subgroup III in Africa, 1989-94. Epidemiol Infect 1996; 116:115-20.

43. Sacchi CT, Pessoa LL, Ramos SR et al. Ongoing group B Neisseria meningitidis epidemic in São Paulo, Brazil, due to increased prevalence of a single clone of the ET-5 complex. J Clin Microbiol 1992; 30:1734-8.

44. Caugant DA, Froholm LO, Selander RK, Bovre K. Sulfonamide resistance in Neisseria meningitidis isolates of clones of the ET-5 complex. Apmis 1989; 97:425-8.

45. Swartley JS, Marfin AA, Edupuganti S et al. Capsule switching of Neisseria meningitidis. Proc Natl Acad Sci U S A 1997; 94:271-6.

46. Puricelli RC, Kupek E, Bertoncini RC. Control of a community outbreak of group C meningococcal meningitis in Corupa, Santa Catarina State, Brazil, based on rapid and effective epidemiological surveillance and immunization. Cad Saúde Pública 2004; 20:959-67.

47. Begg N. Outbreak management. In: Cartwright K, ed. Meningococcal Disease. West Sussex: John Wiley \& Sons, 1995:285305.

48. A.C.I.P. Control and prevention of serogroup C meningococcal disease: evaluation and management of suspected outbreaks: recommendations of the Advisory Committee on Immunization Practices (ACIP). MMWR Recomm Rep 1997; 46:13-21. 
49. Caugant DA. Population genetics and molecular epidemiology of Neisseria meningitidis. Apmis 1998; 106:505-25.

50. W.H.O. Control of edipemic meningococcal disease. World Health Organization, 1998.

51. Brahams D. Meningitis, schools, and public alarm. Lancet 1992; 339:1532.

52. Alcalá B, Arreaza L, Salcedo C, Uría MJ, De La Fuente L, Vázquez JA. Capsule switching among C:2b:P1.2,5 meningococcal epidemic strains after mass immunization campaign, Spain. Emerg Infect Dis 2002; 8(12):1512-4.

53. Stefanelli P, Fazio C, Neri A, Sofia T, Mastrantonio P. Emergence in Italy of a Neisseria meningitidis clone with decreased susceptibility to penicillin. Antimicrob Agents Chemother 2004; 48:3103-6.

54. Arreaza L, Salcedo C, Alcalá B et al. Sequencing of Neisseria meningitidis penA gene: the key to success in defining penicillin G breakpoints. Antimicrob Agents Chemother 2004; 48:358-9.

55. Uriz S, Pineda V, Grau M et al. Neisseria meningitidis with reduced sensitivity to penicillin: observations in 10 children. Scand J Infect Dis 1991; 23:171-174.
56. Woods CR, Smith AL, Wasilauskas BL, Campos J, Givner LB. Invasive disease caused by Neisseria meningitidis relatively resistant to penicillin in North Carolina. J Infect Dis 1994; 170:453-6.

57. Brown S, Riley G, Jamieson F. Neisseria meningitidis with decreased susceptibility to penicillin in Ontario, Canada 19972000. Can Commun Dis Rep 2001; 27:73-5.

58. Vazquez JA, Enriquez R, Abad R, Alcala B, Salcedo C, Arreaza L. Antibiotic resistant meningococci in Europe: any need to act? FEMS Microbiol Rev 2007; 31:64-70.

59. Bell WE. Bacterial meningitis in children. Selected aspects. Pediatr Clin North Am 1992; 39:651-68.

60. Decosas J, Koama JB. Chronicle of an outbreak foretold: meningococcal meningitis $\mathrm{W}_{135}$ in Burkina Faso. Lancet Infect Dis 2002; 2:763-5.

61. Peltola H. Early meningococcal disease: advising the public and the profession. Lancet 1993; 342:509-10.

62. Thomson APJ, Riordan FAI. The management of meningococcal disease. Curr Paediatr 2000; 10:104-9. 